\title{
Multinationals and Futures Hedging under Liquidity Constraints *
}

\author{
Donald LIEN ${ }^{\dagger}$ \\ University of Texas at San Antonio \\ Kit Pong Wong ${ }^{\ddagger}$ \\ University of Hong Kong
}

April 2005

This paper examines the behavior of a multinational firm (MNF) under exchange rate uncertainty. The MNF has operations domiciled in the home country and in a foreign country. Each of these two operations produces a single homogeneous good to be sold in the home and foreign markets. To hedge the exchange rate risk, the MNF has access to an intertemporally unbiased currency futures market. All currency futures contracts are marked-to-market and thus require interim cash settlement of gains and losses. We impose a liquidity constraint on the MNF in that the MNF is forced to prematurely liquidate its futures position from which the interim loss exceeds a predetermined threshold level. If the MNF's utility function satisfies decreasing absolute risk aversion, we show that the MNF optimally opts for a short under-hedge. Furthermore, the MNF sells less (more) and produces more (less) in the foreign (home) country in response to the imposition of the liquidity constraint.

JEL classification: D81; F23; F31

Keywords: Futures; Marking to market; Multinationals; Liquidity constraints

\footnotetext{
*We would like to thank Manuchehr Shahrokhi (the editor) and an anonymous referee for their helpful comments and suggestions. Wong gratefully acknowledges financial support from a grant provided by the University Grants Committee of the Hong Kong Special Administrative Region, China (Project No. AoE/H05/99). The usual disclaimer applies.

${ }^{\dagger}$ Department of Economics, University of Texas at San Antonio, 6900 North Loop 1604 West, San Antonio, TX 78249-0633, U.S.A. Tel.: 210-458-7312; fax: 210-458-5837. E-mail address: dlien@utsa.ed (D. Lien).

${ }^{\ddagger}$ Corresponding author. School of Economics and Finance, University of Hong Kong, Pokfulam Road, Hong Kong. Tel.: 852-2859-1044; fax: 852-2548-1152. E-mail address: kpwong@econ.hku.hk (K. P. Wong).
} 


\title{
Multinationals and futures hedging under liquidity constraints
}

\begin{abstract}
This paper examines the behavior of a multinational firm (MNF) under exchange rate uncertainty. The MNF has operations domiciled in the home country and in a foreign country. Each of these two operations produces a single homogeneous good to be sold in the home and foreign markets. To hedge the exchange rate risk, the MNF has access to an intertemporally unbiased currency futures market. All currency futures contracts are marked-to-market and thus require interim cash settlement of gains and losses. We impose a liquidity constraint on the MNF in that the MNF is forced to prematurely liquidate its futures position from which the interim loss exceeds a predetermined threshold level. If the MNF's utility function satisfies decreasing absolute risk aversion, we show that the MNF optimally opts for a short under-hedge. Furthermore, the MNF sells less (more) and produces more (less) in the foreign (home) country in response to the imposition of the liquidity constraint.
\end{abstract}

JEL classification: D81; F23; F31

Keywords: Futures; Marking to market; Multinationals; Liquidity constraints

\section{Introduction}

According to the Committee on Payments and Settlement Systems (1998), firms should take liquidity risk seriously when devising their risk management strategies. Jorion (2001) categorizes liquidity risk into asset liquidity risk and funding liquidity risk. The former refers to the risk that the liquidation value of the assets differs significantly from the prevailing mark-to-market value. The latter refers to the risk that payment obligations cannot be met due to inability to raise new funds. Even for firms that are technically solvent, liquidity risk can be fatal to them. Prominent examples include the case of Metallgesellschaft and the debacle of Long-Term Capital Management.

The purpose of this paper is to examine the impact of liquidity risk on the behavior of a multinational firm (MNF) facing exchange rate uncertainty. To this end, we develop a two- 
period model of a risk-averse MNF that has operations domiciled in the home country and in a foreign country. Each of these two operations produces a single homogeneous good to be sold in the home and foreign markets. To hedge its exchange rate risk exposure, the MNF has access to an intertemporally unbiased currency futures market. All currency futures contracts are marked-to-market in that they require interim cash settlement of gains and losses. These ex-post funding needs due to the marking-to-market process create liquidity risk vis-à-vis the exchange rate risk. Following Lien (2003) and Wong (2004a, 2004b), we impose a liquidity constraint on the MNF. Specifically, the MNF is forced to prematurely liquidate its futures position whenever the interim loss incurred from this position exceeds a predetermined threshold level.

In the presence of the liquidity constraint, we show that the MNF optimally opts for a short under-hedge if the MNF's preferences satisfy the reasonable behavioral property of decreasing absolute risk aversion (DARA). Under-hedging is called for to strike a balance between the extent of the exchange rate risk and that of the liquidity risk. This is consistent with the normal practice of partial hedging that most companies do not use financial derivatives to completely hedge their risk exposures (see Tufano, 1996; Bodnar, Hayt, \& Marston, 1998).

Owing to the presence of the liquidity constraint, sales in the foreign market are embedded with some residual exchange rate risk that cannot be eliminated. A risk premium is thus demanded by the MNF on its foreign sales. This creates a wedge between the marginal revenues in the home and foreign markets. As a result, the MNF with the DARA utility function sells less (more) and produces more (less) in the foreign (home) country in response to the imposition of the liquidity constraint. These adjustments in sales and outputs result in a lower expected global domestic profit accrued to and a lower expected utility level attainable by the MNF as compared to those in the absence of the liquidity constraint.

The rest of this paper is organized as follows. Section 2 delineates a two-period model of a risk-averse MNF facing both exchange rate risk and liquidity risk. Section 3 derives the MNF's optimal hedging decision. Section 4 examines the impact of the liquidity constraint 
on the MNF's production and sales decisions. The final section concludes.

\section{The model}

Consider a two-period, three-date (indexed by $t=0,1$, and 2) model of a multinational firm (MNF) that has operations domiciled in the home country and in a foreign country. Interest rates in both periods are known with certainty. We as such compound all cash flows to their future values at $t=2$ throughout the paper.

The MNF's home operation produces a single homogeneous good, $x_{H}$, according to a cost function, $C_{H}\left(x_{H}\right)$, denominated in the domestic currency. The MNF's foreign operation produces the same homogeneous good, $x_{F}$, according to a cost function, $C_{F}\left(x_{F}\right)$, denominated in the foreign currency. ${ }^{1}$ The two cost functions, $C_{H}\left(x_{H}\right)$ and $C_{F}\left(x_{F}\right)$, are assumed to be strictly increasing and convex.

At $t=2$, the MNF sells $y_{H}$ units of its total output, $x_{H}+x_{F}$, in the home country and $y_{F}$ units in the foreign country, where $y_{H}+y_{F}=x_{H}+x_{F}$. The sales in the home market generate a revenue function, $R_{H}\left(y_{H}\right)$, denominated in the domestic currency, whereas the sales in the foreign market generate a revenue function, $R_{F}\left(y_{F}\right)$, denominated in the foreign currency. Both $R_{H}\left(y_{H}\right)$ and $R_{F}\left(y_{F}\right)$ are assumed to be strictly increasing and concave, indicating some monopoly power enjoyed by the MNF in the home and foreign markets.

The prevailing spot exchange rate at $t=2$ of the domestic currency against the foreign currency, $\tilde{e}_{2}$, is not known ex ante. ${ }^{2}$ To hedge its exposure to this exchange rate risk, the MNF can trade infinitely divisible contracts in a currency futures market at $t=0$. Each of the currency futures contracts calls for delivery of $f_{0}$ units of the domestic currency per unit of the foreign currency at $t=2$. Let $z$ be the number of the currency futures contracts sold (purchased if negative) by the MNF at $t=0$.

\footnotetext{
${ }^{1}$ The assumption that the MNF's home and foreign operations produce the same homogeneous good is not crucial. In the case of differentiated goods, we wold have two-way trade between the home and foreign operations rather than one-way trade as in the model.

${ }^{2}$ Throughout the paper, random variables have a tilde $(\sim)$ while their realizations do not.
} 
While the initial futures exchange rate, $f_{0}$, is known, the futures exchange rate at $t=1, \tilde{f}_{1}$, is regarded as a positive random variable. Let $\phi\left(f_{1}\right)$ and $\Phi\left(f_{1}\right)$ be the known probability density function and cumulative distribution function of $\tilde{f}_{1}$, respectively, over support $\left[\underline{f}_{1}, \bar{f}_{1}\right]$, where $0<\underline{f}_{1}<\bar{f}_{1}<\infty$. Conditioned on the realized futures exchange rate at $t=1, \tilde{f}_{1}=f_{1}$, the spot exchange rate at $t=2$, which by convergence is also the futures exchange rate at $t=2$, can be specified as $\tilde{e}_{2}=f_{1}+\tilde{\varepsilon}$, where $\tilde{\varepsilon}$ is a random variable. To focus on the MNF's hedging motive, vis-à-vis its speculative motive, we assume that the currency futures market is intertemporally unbiased. That is, we set $f_{0}$ equal to the unconditional expected value of $\tilde{e}_{2}$ and $\tilde{\epsilon}$ equal to a zero-mean random variable conditionally independent of $\tilde{f}_{1}$, thereby rendering $f_{1}$ equal to the conditional expected value of $\tilde{e}_{2}$. Let $\psi(\varepsilon)$ and $\Psi(\varepsilon)$ be the known probability density function and cumulative distribution function of $\tilde{\varepsilon}$, respectively, over support $[\underline{\varepsilon}, \bar{\varepsilon}]$, where $-\underline{f}_{1}<\underline{\varepsilon}<0<\bar{\varepsilon}<\infty$.

All of the currency futures contracts are marked to market at the end of each period. Thus, conditioned on the realized futures exchange rate at $t=1, \tilde{f}_{1}=f_{1}$, the MNF enjoys a gain (or suffer a loss if negative) from its futures position, $z$, equal to $\left(f_{0}-f_{1}\right) z$ at $t=1$. Following Lien (2003) and Wong (2004a, 2004b), we impose a liquidity constraint on the MNF. Specifically, the MNF is forced to prematurely liquidate its futures position at $t=1$ whenever the loss incurred at that time exceeds a predetermined threshold level, $k$, i.e., whenever $\left(f_{1}-f_{0}\right) z>k$. Thus, if $\left(f_{1}-f_{0}\right) z>k$, the MNF prematurely liquidates its futures position at $t=1$, implying that its random global profit at $t=2$, denominated in the domestic currency, is given by

$$
\tilde{\Pi}_{L}=R_{H}\left(y_{H}\right)-C_{H}\left(x_{H}\right)+\left(f_{1}+\tilde{\varepsilon}\right)\left[R_{F}\left(y_{F}\right)-C_{F}\left(x_{F}\right)\right]+\left(f_{0}-f_{1}\right) z .
$$

On the other hand, if $\left(f_{1}-f_{0}\right) z \leq k$, the MNF holds its futures position until $t=2$ so that its random global domestic currency profit at $t=2$ becomes

$$
\tilde{\Pi}_{C}=R_{H}\left(y_{H}\right)-C_{H}\left(x_{H}\right)+\left(f_{1}+\tilde{\varepsilon}\right)\left[R_{F}\left(y_{F}\right)-C_{F}\left(x_{F}\right)\right]+\left(f_{0}-f_{1}-\tilde{\varepsilon}\right) z .
$$

The MNF possesses a von Neumann-Morgenstern utility function, $U(\Pi)$, defined over its global domestic currency profit at $t=2$, $\Pi$, with $U^{\prime}(\Pi)>0$ and $U^{\prime \prime}(\Pi)<0$, indicating 
the presence of risk aversion. ${ }^{3}$ Anticipating the liquidity constraint at $t=1$, the MNF has to choose the levels of output in the home and foreign operations, $x_{H}$ and $x_{F}$, the sales in the home and foreign markets, $y_{H}$ and $y_{F}$, and the futures position, $z$, at $t=0$ so as to maximize the expected utility of its random global domestic currency profit at $t=2$, subject to the constraint that $x_{H}+x_{F}=y_{H}+y_{F}$.

In Appendix A, we show that it is optimal for the MNF to opt for a short futures position, i.e., $z>0$. Thus, the MNF's ex-ante decision problem at $t=0$ is given by

$$
\max _{x_{H}, x_{F}, y_{H}, y_{F}, z} \int_{\underline{f}_{1}}^{f_{0}+k / z} \mathrm{E}_{\varepsilon}\left[U\left(\tilde{\Pi}_{C}\right)\right] \mathrm{d} \Phi\left(f_{1}\right)+\int_{f_{0}+k / z}^{\bar{f}_{1}} \mathrm{E}_{\varepsilon}\left[U\left(\tilde{\Pi}_{L}\right)\right] \mathrm{d} \Phi\left(f_{1}\right)
$$

subject to $x_{H}+x_{F}=y_{H}+y_{F}$, where $\mathrm{E}_{\varepsilon}(\cdot)$ is the expectation operator with respect to $\Psi(\varepsilon)$, and $\tilde{\Pi}_{L}$ and $\tilde{\Pi}_{C}$ are defined in equations (1) and (2), respectively.

\section{Optimal hedging decision}

Assuming an interior optimal solution and making use of the constraint that $y_{F}=$ $x_{H}+x_{F}-y_{H}$, the first-order conditions for program (3) with respect to $x_{H}, x_{F}, y_{H}$, and $z$ are respectively given by 4

$$
\begin{aligned}
& \int_{\underline{f}_{1}}^{f_{0}+k / z^{*}} \mathrm{E}_{\varepsilon}\left\{U^{\prime}\left(\tilde{\Pi}_{C}^{*}\right)\left[\left(f_{1}+\tilde{\varepsilon}\right) R_{F}^{\prime}\left(y_{F}^{*}\right)-C_{H}^{\prime}\left(x_{H}^{*}\right)\right]\right\} \mathrm{d} \Phi\left(f_{1}\right) \\
& \quad+\int_{f_{0}+k / z^{*}}^{\bar{f}_{1}} \mathrm{E}_{\varepsilon}\left\{U^{\prime}\left(\tilde{\Pi}_{L}^{*}\right)\left[\left(f_{1}+\tilde{\varepsilon}\right) R_{F}^{\prime}\left(y_{F}^{*}\right)-C_{H}^{\prime}\left(x_{H}^{*}\right)\right]\right\} \mathrm{d} \Phi\left(f_{1}\right)=0, \\
& \int_{\underline{f}_{1}}^{f_{0}+k / z^{*}} \mathrm{E}_{\varepsilon}\left\{U^{\prime}\left(\tilde{\Pi}_{C}^{*}\right)\left(f_{1}+\tilde{\varepsilon}\right)\left[R_{F}^{\prime}\left(y_{F}^{*}\right)-C_{F}^{\prime}\left(x_{F}^{*}\right)\right]\right\} \mathrm{d} \Phi\left(f_{1}\right)
\end{aligned}
$$

\footnotetext{
${ }^{3}$ If the MNF is risk neutral, hedging with the intertemporally unbiased currency futures contracts adds no value to the MNF. The assumption of risk aversion can be justified by the prevalence of corporate taxes, costs of financial distress, or capital market imperfections (see Stulz, 1996).

${ }^{4}$ Sufficient conditions for an interior optimal solution are that $R_{H}^{\prime}(0)=R_{F}^{\prime}(0)=\infty, R_{H}^{\prime}(\infty)=R_{F}^{\prime}(\infty)=$ $0, C_{H}^{\prime}(0)=C_{F}^{\prime}(0)=0$, and $C_{H}^{\prime}(\infty)=C_{F}^{\prime}(\infty)=\infty$.
} 


$$
\begin{gathered}
+\int_{f_{0}+k / z^{*}}^{\bar{f}_{1}} \mathrm{E}_{\varepsilon}\left\{U^{\prime}\left(\tilde{\Pi}_{L}^{*}\right)\left(f_{1}+\tilde{\varepsilon}\right)\left[R_{F}^{\prime}\left(y_{F}^{*}\right)-C_{F}^{\prime}\left(x_{F}^{*}\right)\right]\right\} \mathrm{d} \Phi\left(f_{1}\right)=0, \\
\int_{\underline{f}_{1}}^{f_{0}+k / z^{*}} \mathrm{E}_{\varepsilon}\left\{U^{\prime}\left(\tilde{\Pi}_{C}^{*}\right)\left[R_{H}^{\prime}\left(y_{H}^{*}\right)-\left(f_{1}+\tilde{\varepsilon}\right) R_{F}^{\prime}\left(y_{F}^{*}\right)\right]\right\} \mathrm{d} \Phi\left(f_{1}\right) \\
+\int_{f_{0}+k / z^{*}}^{\bar{f}_{1}} \mathrm{E}_{\varepsilon}\left\{U^{\prime}\left(\tilde{\Pi}_{L}^{*}\right)\left[R_{H}^{\prime}\left(y_{H}^{*}\right)-\left(f_{1}+\tilde{\varepsilon}\right) R_{F}^{\prime}\left(y_{F}^{*}\right)\right]\right\} \mathrm{d} \Phi\left(f_{1}\right)=0, \\
\int_{\underline{f}_{1}}^{f_{0}+k / z^{*}} \mathrm{E}_{\varepsilon}\left[U^{\prime}\left(\tilde{\Pi}_{C}^{*}\right)\left(f_{0}-f_{1}-\tilde{\varepsilon}\right)\right] \mathrm{d} \Phi\left(f_{1}\right)+\int_{f_{0}+k / z^{*}}^{\bar{f}_{1}} \mathrm{E}_{\varepsilon}\left[U^{\prime}\left(\tilde{\Pi}_{L}^{*}\right)\right]\left(f_{0}-f_{1}\right) \mathrm{d} \Phi\left(f_{1}\right) \\
+\mathrm{E}_{\varepsilon}\left[U\left(\tilde{\Pi}_{L 0}^{*}\right)-U\left(\tilde{\Pi}_{C 0}^{*}\right)\right] \phi\left(f_{0}+k / z^{*}\right) k / z^{* 2}=0,
\end{gathered}
$$

where we have used Leibniz's rule,

$$
\begin{aligned}
& \tilde{\Pi}_{L 0}^{*}=R_{H}\left(y_{H}^{*}\right)-C_{H}\left(x_{H}^{*}\right)+\left(f_{0}+k / z^{*}+\tilde{\varepsilon}\right)\left[R_{F}\left(y_{F}^{*}\right)-C_{F}\left(y_{F}^{*}\right)\right]-k, \\
& \tilde{\Pi}_{C 0}^{*}=R_{H}\left(y_{H}^{*}\right)-C_{H}\left(x_{H}^{*}\right)+\left(f_{0}+k / z^{*}+\tilde{\varepsilon}\right)\left[R_{F}\left(y_{F}^{*}\right)-C_{F}\left(y_{F}^{*}\right)\right]-k-\tilde{\varepsilon} z^{*},
\end{aligned}
$$

and an asterisk $(*)$ indicates an optimal level.

As is well known in the literature, under multiple sources of risk, risk aversion alone is usually too weak to yield intuitively appealing results and decreasing absolute risk aversion (DARA) is called for (see Gollier, 2001). The MNF's utility function, $U(\Pi)$, exhibits DARA if, and only if, the Arrow-Pratt measure of absolute risk aversion, $-U^{\prime \prime}(\Pi) / U^{\prime}(\Pi)$, decreases with $\Pi$.

Proposition 1: If the MNF's utility function exhibits DARA and the currency futures market is intertemporally unbiased, then the MNF facing the liquidity constraint optimally opts for a short under-hedge futures position, i.e., $0<z^{*}<R_{F}\left(y_{F}^{*}\right)-C_{F}\left(x_{F}^{*}\right)$.

Proof: See Appendix B. 
To see the intuition of Proposition 1, we refer to equations (1) and (2). If the MNF faces no liquidity constraints, its random global domestic currency profit at $t=2$ is delineated solely by equation (2). In this case, the full-hedging theorem of Danthine (1976), Holthausen (1979), Feder, Just, and Schmitz (1980), Broll and Zilcha (1992), and Broll, Wong, and Zilcha (1999) applies in that setting $z=R_{F}\left(y_{F}\right)-C_{F}\left(x_{F}\right)$ completely eliminates the exchange rate risk. In the presence of the liquidity constraint, however, such a full-hedge is no longer optimal due to the residual risk, $\tilde{\varepsilon}\left[R_{F}\left(y_{F}\right)-C_{F}\left(x_{F}\right)\right]$, arising from the premature liquidation of the futures position at $t=1$, as evident from equation (1). This creates an income effect because the presence of the liquidity risk reduces the attainable expected utility under risk aversion. To attain the former expected utility level (with no risk), the MNF has to be compensated with additional income. Taking away this compensation gives rise to the income effect (see Wong, 1997). Under DARA, the MNF becomes more risk averse and thus is unwilling to take on the liquidity risk. The MNF as such shorts less of the currency futures contracts so as to shrink the interval, $\left[f_{0}+k / z, \bar{f}_{1}\right]$, over which the premature liquidation of the futures position at $t=1$ prevails. It is therefore optimal for the MNF to set $z<R_{F}\left(y_{F}\right)-C_{F}\left(x_{F}\right)$ that strikes a balance between the extent of the exchange rate risk and that of the liquidity risk.

When $k=\infty$, the MNF's liquidity constraint never binds and a full-hedge is optimal. When $k$ is finite, the liquidity constraint is in effect with positive probability and an underhedge becomes optimal according to Proposition 1. Thus, the severity of the liquidity constraint, as gauged by the threshold, $k$, plays a pivotal role in shaping the MNF's optimal futures position, $z^{*}$.

Tufano (1996) documents that in the gold mining industry only $17 \%$ of firms shed $40 \%$ or more of their price risk. Bodnar, Hayt, and Marston (1998) also find that most nonfinancial firms do not use financial derivatives to completely hedge their risk exposures. Such a normal practice of partial hedging may be due to the prevalence of liquidity constraints confronted by firms, as suggested by Proposition 1 . 


\section{Optimal production and sales decisions}

If the MNF faces no liquidity constraints, we know from Broll and Zilcha (1992) and Broll, Wong, and Zilcha (1999) that the separation theorem of Danthine (1976), Holthausen (1979), and Feder, Just, and Schmitz (1980) holds. Specifically, the optimal sales and outputs in this case are given by ${ }^{5}$

$$
\begin{aligned}
& R_{H}^{\prime}\left(y_{H}^{0}\right)=C_{H}^{\prime}\left(x_{H}^{0}\right), \\
& R_{F}^{\prime}\left(y_{F}^{0}\right)=C_{F}^{\prime}\left(x_{F}^{0}\right), \\
& R_{H}^{\prime}\left(y_{H}^{0}\right)=f_{0} R_{F}^{\prime}\left(y_{F}^{0}\right),
\end{aligned}
$$

where a nought $\left({ }^{0}\right)$ indicates an optimal level in the absence of the liquidity constraint.

Proposition 2: If the MNF's utility function exhibits DARA and the currency futures market is intertemporally unbiased, then imposing the liquidity constraint onto the MNF induces a lower level of output in the home operation, $x_{H}^{*}<x_{H}^{0}$, a higher level of output in the foreign operation, $x_{F}^{*}>x_{F}^{0}$, a higher level of sales in the home market, $y_{H}^{*}>y_{H}^{0}$, and a lower level of sales in the foreign market, $y_{F}^{*}<y_{F}^{0}$.

Proof: See Appendix C.

To see the intuition of Proposition 2, we refer to equations (1) and (2). If the MNF faces no liquidity constraints, its random global domestic currency profit at $t=2$ is given by equation (2) only. In this case, the MNF could have completely eliminated its exposure to the exchange rate risk had it chosen $z=R_{F}\left(y_{F}\right)-C_{F}\left(y_{F}\right)$ within its own discretion. Alternatively put, the degree of exchange rate risk exposure to be assumed by the MNF should be totally unrelated to its sales and production decisions. The optimal sales and outputs are then chosen to maximize $R_{H}\left(y_{H}\right)-C_{H}\left(x_{H}\right)+f_{0}\left[R_{F}\left(y_{F}\right)-C_{F}\left(x_{F}\right)\right]$, thereby yielding

\footnotetext{
${ }^{5}$ Equations (10), (11), and (12) follow immediately from equations (4), (5), (6), and (7) by setting $k=\infty$.
} 
equations (10), (11), and (12). Equations (10) and (11) state that the MNF equates the marginal revenues to the marginal costs in both the home and foreign markets, respectively. Furthermore, equation (12) reveals that the marginal revenue in the home market is equal to the expected marginal revenue in the foreign market, both of which are denominated in the domestic currency. This is the celebrated separation theorem of Danthine (1978), Holthausen (1979), and Feder, Just, and Schmitz (1980).

In the presence of the liquidity constraint, setting $z=R_{F}\left(y_{F}\right)-C_{F}\left(x_{F}\right)$ cannot eliminate all the exchange rate risk due to the residual risk, $\tilde{\varepsilon}\left[R_{F}\left(y_{F}\right)-C_{F}\left(x_{F}\right)\right]$, arising from the premature liquidation of the futures position at $t=1$. Such residual risk, however, can be controlled by varying the levels of output and sales. Equations (20) and (21) state that it remains optimal for the $\mathrm{MNF}$ to equate the marginal revenues to the marginal costs in both the home and foreign markets, respectively. However, equation (22) implies that the marginal revenue in the home market is strictly less than the expected marginal revenue in the foreign market, both of which are denominated in the domestic currency. Since the sales in the foreign market are embedded with some exchange rate risk that cannot be eliminated due to the liquidity constraint, the MNF has to demand a risk premium to compensate for its foreign sales. The wedge between the two marginal revenues in the home and foreign markets is de facto the risk premium required by the MNF. The MNF as such sells less (more) and produces more (less) in the foreign (home) country. This is in line with the findings of Broll and Zilcha (1992) and Broll, Wong, and Zilcha (1999).

In the absence of the liquidity constraint, the MNF optimally adopts a full-hedge that eliminates all the exchange rate risk. The MNF then chooses its sales and outputs so as to maximize its expected global domestic currency profit at $t=2$. In the presence of the liquidity constraint, the MNF adjusts its sales and outputs according to Proposition 2 by selling less (more) and producing more (less) in the foreign (home) country. This must imply the MNF's expected global domestic currency profit at $t=2$ be adversely affected in face of the liquidity risk. Given risk aversion, the MNF's expected utility must also be lowered. Thus, the presence of the liquidity constraint unambiguously makes the MNF strictly worse off regarding to both its profit and utility levels. 


\section{Conclusions}

In this paper, we have examined the behavior of a risk-averse multinational firm (MNF) under exchange rate uncertainty. The MNF has operations domiciled in the home country and in a foreign country. Each of these two operations produces a single homogeneous good to be sold in the home and foreign markets. To hedge its exchange rate exposure, the MNF has access to an intertemporally unbiased currency futures market. All currency futures contracts are marked-to-market and thus require interim cash settlement of gains and losses. These ex-post funding needs due to the marking-to-market process create liquidity risk vis-àvis the exchange rate risk. As in Lien (2003) and Wong (2004a, 2004b), the MNF is liquidity constrained in that it is forced to prematurely liquidate its futures position whenever the interim loss incurred from this position exceeds a predetermined threshold level.

Within our context, we have shown that the MNF optimally opts for a short underhedge should the MNF's preferences satisfy decreasing absolute risk aversion (DARA). We have further shown that the MNF with the DARA utility function sells less (more) and produces more (less) in the foreign (home) country in response to the imposition of the liquidity constraint. The liquidity risk created by the interim funding requirement of a futures hedge thus bestows perverse incentives on the MNF regarding to its hedging and production decisions. These result in a lower expected global domestic profit accrued to and a lower expected utility level attainable by the MNF as compared to those in the absence of the liquidity constraint, thereby making the MNF strictly worse off. 


\section{Appendix A}

The expected utility of the MNF's random domestic currency profit at $t=2$ is given by

$$
E U= \begin{cases}\int_{\underline{f}_{1}}^{f_{0}+k / z} \mathrm{E}_{\varepsilon}\left[U\left(\tilde{\Pi}_{C}\right)\right] \mathrm{d} \Phi\left(f_{1}\right)+\int_{f_{0}+k / z}^{\bar{f}_{1}} \mathrm{E}_{\varepsilon}\left[U\left(\tilde{\Pi}_{L}\right)\right] \mathrm{d} \Phi\left(f_{1}\right) & \text { if } z>0 \\ \int_{\underline{f}_{1}}^{\bar{f}_{1}} \mathrm{E}_{\varepsilon}\left[U\left(\tilde{\Pi}_{0}\right)\right] \mathrm{d} \Phi\left(f_{1}\right) & \text { if } z=0 \\ \int_{\underline{f}_{1}}^{f_{0}+k / z} \mathrm{E}_{\varepsilon}\left[U\left(\tilde{\Pi}_{L}\right)\right] \mathrm{d} \Phi\left(f_{1}\right)+\int_{f_{0}+k / z}^{\bar{f}_{1}} \mathrm{E}_{\varepsilon}\left[U\left(\tilde{\Pi}_{C}\right)\right] \mathrm{d} \Phi\left(f_{1}\right) & \text { if } z<0\end{cases}
$$

where $\tilde{\Pi}_{0}=R_{H}\left(y_{H}\right)-C_{H}\left(x_{H}\right)+\left(f_{1}+\tilde{\varepsilon}\right)\left[R_{F}\left(y_{F}\right)-C_{F}\left(x_{F}\right)\right], \mathrm{E}_{\varepsilon}(\cdot)$ is the expectation operator with respect to $\Psi(\varepsilon)$, and $\tilde{\Pi}_{L}$ and $\tilde{\Pi}_{C}$ are defined in equations (1) and (2), respectively. To solve the MNF's ex-ante decision problem at $t=0$, we need to know which expression on the right-hand side of equation (13) contains the solution.

Consider first the case where $z>0$. Using Leibniz's rule to partially differentiate $E U$ as defined in equation (13) with respect to $z$ and evaluating the resulting derivative at $z \rightarrow 0^{+}$ yields

$$
\lim _{z \rightarrow 0^{+}} \frac{\partial E U}{\partial z}=\int_{\underline{f}_{1}}^{\bar{f}_{1}} \mathrm{E}_{\varepsilon}\left[U^{\prime}\left(\tilde{\Pi}_{0}\right)\left(f_{0}-f_{1}-\tilde{\varepsilon}\right)\right] \mathrm{d} \Phi\left(f_{1}\right) .
$$

Since $f_{0}$ is set equal to the expected value of $\tilde{e}_{2}=\tilde{f}_{1}+\tilde{\varepsilon}$ with respect to $\phi\left(f_{1}\right) \psi(\varepsilon)$, the right-hand side of equation (14) is simply the negative of the covariance between $U^{\prime}\left(\tilde{\Pi}_{0}\right)$ and $\tilde{f}_{1}+\tilde{\varepsilon}$ with respect to $\phi\left(f_{1}\right) \psi(\varepsilon)$. It follows from risk aversion that $\lim _{z \rightarrow 0^{+}} \partial E U / \partial z>0$.

Now, consider the case where $z<0$. Using Leibniz's rule to partially differentiate $E U$ as defined in equation (13) with respect to $z$ and evaluating the resulting derivative at $z \rightarrow 0^{-}$ yields

$$
\lim _{z \rightarrow 0^{-}} \frac{\partial E U}{\partial z}=\int_{\underline{f}_{1}}^{\bar{f}_{1}} \mathrm{E}_{\varepsilon}\left[U^{\prime}\left(\tilde{\Pi}_{0}\right)\left(f_{0}-f_{1}-\tilde{\varepsilon}\right)\right] \mathrm{d} \Phi\left(f_{1}\right) .
$$

Inspection of equations (14) and (15) reveals that $\lim _{z \rightarrow 0^{+}} \partial E U / \partial z=\lim _{z \rightarrow 0^{-}} \partial E U / \partial z>$ 0 . Since $E U$ as defined in equation (13) is strictly concave, the MNF must optimally opt for $z>0$. 


\section{Appendix B}

Let $E U$ be the objective function in program (3). Partially differentiating $E U$ with respect to $z$ and evaluating the resulting derivative at $x_{H}=x_{H}^{*}, x_{F}=x_{F}^{*}, y_{H}=y_{H}^{*}$, $y_{F}=y_{F}^{*}$, and $z=R_{F}\left(y_{F}^{*}\right)-C_{F}\left(x_{F}^{*}\right)$ yields

$$
\begin{aligned}
\frac{\partial E U}{\partial z}= & \int_{\underline{f}_{1}}^{f_{0}+k /\left[R_{F}\left(y_{F}^{*}\right)-C_{F}\left(x_{F}^{*}\right)\right]} U^{\prime}\left(\Pi_{C 1}^{*}\right) \mathrm{E}_{\varepsilon}\left(f_{0}-f_{1}-\tilde{\varepsilon}\right) \mathrm{d} \Phi\left(f_{1}\right) \\
& +\int_{f_{0}+k /\left[R_{F}\left(y_{F}^{*}\right)-C_{F}\left(x_{F}^{*}\right)\right]}^{\bar{f}_{1}} \mathrm{E}_{\varepsilon}\left[U^{\prime}\left(\tilde{\Pi}_{L 1}^{*}\right)\right]\left(f_{0}-f_{1}\right) \mathrm{d} \Phi\left(f_{1}\right) \\
& +\left\{\mathrm{E}_{\varepsilon}\left[U\left(\tilde{\Pi}_{L 1}^{*}\right)\right]-U\left(\Pi_{C 1}^{*}\right)\right\} \\
& \times \phi\left[f_{0}+\frac{k}{R_{F}\left(y_{F}^{*}\right)-C_{F}\left(x_{F}^{*}\right)}\right] \frac{k}{\left[R_{F}\left(y_{F}^{*}\right)-C_{F}\left(x_{F}^{*}\right)\right]^{2}},
\end{aligned}
$$

where we have used Leibniz's rule, and

$$
\begin{aligned}
& \tilde{\Pi}_{L 1}^{*}=R_{H}\left(y_{H}^{*}\right)-C_{H}\left(x_{H}^{*}\right)+\left(f_{0}+\tilde{\varepsilon}\right)\left[R_{F}\left(y_{F}^{*}\right)-C_{F}\left(x_{F}^{*}\right)\right], \\
& \Pi_{C 1}^{*}=R_{H}\left(y_{H}^{*}\right)-C_{H}\left(x_{H}^{*}\right)+f_{0}\left[R_{F}\left(y_{F}^{*}\right)-C_{F}\left(x_{F}^{*}\right)\right] .
\end{aligned}
$$

If the right-hand side of equation (16) is negative (positive), it follows from equation (7) and the second-order conditions for program (3) that $z^{*}<(>) R_{F}\left(y_{F}^{*}\right)-C_{F}\left(x_{F}^{*}\right)$.

Since $\mathrm{E}_{\varepsilon}(\tilde{\varepsilon})=0$ and $f_{0}$ is set equal to the expected value of $\tilde{f}_{1}$ with respect to $\Phi\left(f_{1}\right)$, we can write equation (16) as

$$
\begin{aligned}
\frac{\partial E U}{\partial z}= & \left\{\mathrm{E}_{\varepsilon}\left[U^{\prime}\left(\tilde{\Pi}_{L 1}^{*}\right)\right]-U^{\prime}\left(\Pi_{C 1}^{*}\right)\right\} \int_{f_{0}+k /\left[R_{F}\left(y_{F}^{*}\right)-C_{F}\left(x_{F}^{*}\right)\right]}^{\bar{f}_{1}}\left(f_{0}-f_{1}\right) \mathrm{d} \Phi\left(f_{1}\right) \\
& +\left\{\mathrm{E}_{\varepsilon}\left[U\left(\tilde{\Pi}_{L 1}^{*}\right)\right]-U\left(\Pi_{C 1}^{*}\right)\right\} \\
& \times \phi\left[f_{0}+\frac{k}{R_{F}\left(y_{F}^{*}\right)-C_{F}\left(x_{F}^{*}\right)}\right] \frac{k}{\left[R_{F}\left(y_{F}^{*}\right)-C_{F}\left(x_{F}^{*}\right)\right]^{2}} .
\end{aligned}
$$

Since $\mathrm{E}_{\varepsilon}(\tilde{\varepsilon})=0$, it follows from equations (17) and (18), risk aversion, and Jensen's inequality that $U\left(\Pi_{C 1}^{*}\right)>\mathrm{E}_{\varepsilon}\left[U\left(\tilde{\Pi}_{L 1}^{*}\right)\right]$ and thus the second term on the right-hand side of 
equation (19) is unambiguously negative. Since $U(\Pi)$ exhibits DARA, we have $U^{\prime \prime \prime}(\Pi) \geq 0$. It follows from $\mathrm{E}_{\varepsilon}(\tilde{\varepsilon})=0$, equations (17) and (18), and Jensen's inequality that $U^{\prime}\left(\Pi_{C 1}^{*}\right) \leq$ $\mathrm{E}_{\varepsilon}\left[U^{\prime}\left(\tilde{\Pi}_{L 1}^{*}\right)\right]$. Thus, the first term on the right-hand side of equation (19) is also unambiguously negative, implying that $z^{*}<R_{F}\left(y_{F}^{*}\right)-C_{F}\left(x_{F}^{*}\right)$.

\section{Appendix C}

Substituting equation (6) into equation (4) yields

$$
R_{H}^{\prime}\left(y_{H}^{*}\right)=C_{H}^{\prime}\left(x_{H}^{*}\right)
$$

since $U^{\prime}(\Pi)>0$. Also, $U^{\prime}(\Pi)>0$ implies that equation (5) reduces to

$$
R_{F}^{\prime}\left(y_{F}^{*}\right)=C_{F}^{\prime}\left(x_{F}^{*}\right)
$$

Substituting equation (7) into equation (6) yields

$$
R_{H}^{\prime}\left(y_{H}^{*}\right)+\Theta=f_{0} R_{F}^{\prime}\left(y_{F}^{*}\right)
$$

where $\Theta$ is defined by $R_{F}^{\prime}\left(y_{F}^{*}\right)$ times

$$
\frac{\mathrm{E}_{\varepsilon}\left[U\left(\tilde{\Pi}_{C 0}^{*}\right)-U\left(\tilde{\Pi}_{L 0}^{*}\right)\right] \phi\left(f_{0}+k / z^{*}\right) k / z^{* 2}-\int_{f_{0}+k / z^{*}}^{\bar{f}_{1}} \mathrm{E}_{\varepsilon}\left[U^{\prime}\left(\tilde{\Pi}_{L}^{*}\right) \tilde{\varepsilon}\right] \mathrm{d} \Phi\left(f_{1}\right)}{\int_{\underline{f}_{1}+k / z^{*}}^{f_{1}} \mathrm{E}_{\varepsilon}\left[U^{\prime}\left(\tilde{\Pi}_{C}^{*}\right)\right] \mathrm{d} \Phi\left(f_{1}\right)+\int_{f_{0}+k / z^{*}}^{\bar{f}_{1}} \mathrm{E}_{\varepsilon}\left[U^{\prime}\left(\tilde{\Pi}_{L}^{*}\right)\right] \mathrm{d} \Phi\left(f_{1}\right)} .
$$

Since $\mathrm{E}_{\varepsilon}(\tilde{\varepsilon})=0$, it follows from equation (1) and risk aversion that $\mathrm{E}_{\varepsilon}\left[U^{\prime}\left(\tilde{\Pi}_{L}^{*}\right) \tilde{\varepsilon}\right]=$ $\operatorname{Cov}_{\varepsilon}\left[U^{\prime}\left(\tilde{\Pi}_{L}^{*}\right), \tilde{\varepsilon}\right]<0$. Thus, the second term in the numerator of expression (23) is unambiguously positive. The first term in the numerator of expression (23) has the same sign as $\mathrm{E}_{\varepsilon}\left[U\left(\tilde{\Pi}_{C 0}^{*}\right)-U\left(\tilde{\Pi}_{L 0}^{*}\right)\right]$.

From Proposition 1, we know that $0<z^{*}<R_{F}\left(y_{F}^{*}\right)-C_{F}\left(x_{F}^{*}\right)$. Let $F\left(\Pi_{L 0}^{*}\right)$ be the cumulative distribution function of $\tilde{\Pi}_{L 0}^{*}$. Using the change-of-variable technique (see Hogg 
\& Craig, 1989), $\tilde{\Pi}_{L 0}^{*}$ has support $[M+\underline{\varepsilon} Q, M+\bar{\varepsilon} Q]$ and $F\left(\Pi_{L 0}^{*}\right)=\Psi\left[\left(\Pi_{L 0}^{*}-M\right) / Q\right]$, where $M=R_{H}\left(y_{H}^{*}\right)-C_{H}\left(x_{H}^{*}\right)+\left(f_{0}+k / z^{*}\right) Q-k$ and $Q=R_{F}\left(y_{F}^{*}\right)-C_{F}\left(x_{F}^{*}\right)$. Thus, we can write

$$
\mathrm{E}_{\varepsilon}\left[U^{\prime}\left(\tilde{\Pi}_{L 0}^{*}\right)\right]=\int_{M+\underline{\varepsilon} Q}^{M+\bar{\varepsilon} Q} U^{\prime}(X) \mathrm{d} F(X) .
$$

Likewise, let $G\left(\Pi_{C 0}^{*}\right)$ be the cumulative distribution function of $\tilde{\Pi}_{C 0}^{*}$. Using the changeof-variable technique, $\tilde{\Pi}_{C 0}^{*}$ has support $\left[M+\underline{\varepsilon}\left(Q-z^{*}\right), M+\bar{\varepsilon}\left(Q-z^{*}\right)\right]$ and $G\left(\Pi_{C 0}^{*}\right)=$ $F\left[\Pi_{C 0}^{*}+\left(\Pi_{C 0}^{*}-M\right) z^{*} /\left(Q-z^{*}\right)\right]$. Thus, we can write

$$
\mathrm{E}_{\varepsilon}\left[U^{\prime}\left(\tilde{\Pi}_{C 0}^{*}\right)\right]=\int_{M+\underline{\epsilon}\left(Q-z^{*}\right)}^{M+\bar{\epsilon}\left(Q-z^{*}\right)} U^{\prime}(X) \mathrm{d} G(X) .
$$

Subtracting equation (25) by equation (24) yields

$$
\mathrm{E}_{\varepsilon}\left[U\left(\tilde{\Pi}_{C 0}^{*}\right)-U\left(\tilde{\Pi}_{L 0}^{*}\right)\right]=\int_{M+\underline{\epsilon} Q}^{M+\bar{\epsilon} Q} U^{\prime}(X) \mathrm{d}[G(X)-F(X)],
$$

which follows from the fact that $\mathrm{d} G(X)=0$ for all $X \in\left[M+\underline{\varepsilon} Q, M+\underline{\varepsilon}\left(Q-z^{*}\right)\right] \cup[M+$ $\left.\bar{\varepsilon}\left(Q-z^{*}\right), M+\bar{\varepsilon} Q\right]$.

Consider the function, $T(X)=\int_{M+\underline{\varepsilon} Q}^{X}[F(Y)-G(Y)] \mathrm{d} Y$, for all $X \in[M+\underline{\varepsilon} Q, M+\bar{\varepsilon} Q]$. Then, we can write

$$
T(X)=\left\{\begin{array}{r}
\int_{M+\underline{\varepsilon} Q}^{X} F(Y) \mathrm{d} Y \\
\quad \text { if } M+\underline{\varepsilon} Q \leq X<M+\underline{\varepsilon}\left(Q-z^{*}\right), \\
\int_{M+\underline{\varepsilon} Q}^{X} F(Y) \mathrm{d} Y-\int_{M+\underline{\varepsilon}\left(Q-z^{*}\right)}^{X} G(Y) \mathrm{d} Y \\
\text { if } M+\underline{\varepsilon}\left(Q-z^{*}\right) \leq X \leq M+\bar{\varepsilon}\left(Q-z^{*}\right), \\
\int_{M+\underline{\varepsilon} Q}^{X} F(Y) \mathrm{d} Y-\int_{M+\underline{\varepsilon}\left(Q-z^{*}\right)}^{M+\bar{\varepsilon}\left(Q-z^{*}\right)} G(Y) \mathrm{d} Y-\int_{M+\bar{\varepsilon}\left(Q-z^{*}\right)}^{X} \mathrm{~d} Y \\
\text { if } M+\bar{\varepsilon}\left(Q-z^{*}\right)<X \leq M+\bar{\varepsilon} Q,
\end{array}\right.
$$

which follows from the fact that $\mathrm{d} G(X)=0$ for all $X \in\left[M+\underline{\varepsilon} Q, M+\underline{\varepsilon}\left(Q-z^{*}\right)\right] \cup[M+$ $\left.\bar{\varepsilon}\left(Q-z^{*}\right), M+\bar{\varepsilon} Q\right]$. Differentiating $T(X)$ with respect to $X$ and using Leibniz's rule yields

$$
T^{\prime}(X)= \begin{cases}F(X) & \text { if } M+\underline{\varepsilon} Q \leq X<M+\underline{\varepsilon}\left(Q-z^{*}\right), \\ F(X)-G(X) & \text { if } M+\underline{\varepsilon}\left(Q-z^{*}\right) \leq X \leq M+\bar{\epsilon}\left(Q^{*}-H^{*}\right), \\ \Phi(X)-1 & \text { if } M+\bar{\varepsilon}\left(Q-z^{*}\right)<X \leq M+\bar{\varepsilon} Q .\end{cases}
$$


It follows from $G(X)=F\left[X+(X-M) z^{*} /\left(Q-z^{*}\right)\right]$ that $F(X)-G(X)>(<) 0$ if $X<(>) M$. Hence, $T(X)$ is strictly increasing for all $X \in(M+\underline{\varepsilon} Q, M)$ and strictly decreasing for all $X \in(M, M+\bar{\varepsilon} Q)$. Note that

$$
\begin{aligned}
T(M+\bar{\varepsilon} Q)= & \int_{M+\underline{\varepsilon} Q}^{M+\bar{\varepsilon} Q} F(Y) \mathrm{d} Y-\int_{M+\underline{\varepsilon}\left(Q-z^{*}\right)}^{M+\bar{\varepsilon}\left(Q-z^{*}\right)} G(Y) \mathrm{d} Y-\int_{M+\bar{\varepsilon}\left(Q-z^{*}\right)}^{M+\bar{\varepsilon} Q} \mathrm{~d} Y \\
= & M+\bar{\varepsilon} Q-\int_{M+\underline{\varepsilon} Q}^{M+\bar{\varepsilon} Q} Y \mathrm{~d} F(Y)-\left[M+\bar{\varepsilon}\left(Q-z^{*}\right)\right] \\
& +\int_{M+\underline{\varepsilon}\left(Q-z^{*}\right)}^{M+\bar{\varepsilon}\left(Q-z^{*}\right)} Y \mathrm{~d} G(Y)-\int_{M+\bar{\varepsilon}\left(Q-z^{*}\right)}^{M+\bar{\varepsilon} Q} \mathrm{~d} Y \\
= & 0
\end{aligned}
$$

where the second equality follows from integration by parts and the fact that $F(M+\underline{\varepsilon} Q)=$ $G\left[M+\underline{\varepsilon}\left(Q-z^{*}\right)\right]=0$ and $F(M+\bar{\varepsilon} Q)=G\left[M+\bar{\varepsilon}\left(Q-z^{*}\right)\right]=1$. Since $T(M+\underline{\varepsilon} Q)=$ $T(M+\bar{\varepsilon} Q)=0$ and $T(X)$ is first increasing and then decreasing in $X$, it must be true that $T(X)>0$ for all $X \in(M+\underline{\varepsilon} Q, M+\bar{\varepsilon} Q)$. In other words, $F(X)$ is a mean preserving spread of $G(X)$ in the sense of Rothschild and Stiglitz (1970). According to Rothschild and Stiglitz (1971), the right-hand side of equation (26) is unambiguously positive given risk aversion and thus $\Theta>0$.

Suppose that $x_{H}^{*} \geq x_{H}^{0}$. Equations (10) and (20) imply that $y_{H}^{*} \leq y_{H}^{0}$. It then follows from $\Theta>0$ and equations (12) and (22) that $y_{F}^{*}<y_{F}^{0}$. Equations (11) and (21) thus imply that $x_{F}^{*}>x_{F}^{0}$. Since $y_{H}^{*} \leq y_{H}^{0}, y_{F}^{*}<y_{F}^{0}$, and $x_{F}^{*}>x_{F}^{0}$, it must be true that $x_{H}^{*}<x_{H}^{0}$, a contradiction. Likewise, suppose that $x_{F}^{*} \leq x_{F}^{0}$. Equations (11) and (21) imply that $y_{F}^{*} \geq y_{F}^{0}$. It then follows from $\Theta>0$ and equations (12) and (22) that $y_{H}^{*}>y_{H}^{0}$. Equations (10) and (20) thus imply that $x_{H}^{*}<x_{H}^{0}$. Since $y_{H}^{*}>y_{H}^{0}, y_{F}^{*} \geq y_{F}^{0}$, and $x_{H}^{*}<x_{H}^{0}$, it must be true that $x_{F}^{*}>x_{F}^{0}$, a contradiction. Hence, we conclude that $x_{H}^{*}<x_{H}^{0}$ and $x_{F}^{*}>x_{F}^{0}$ and from equations (10), (11), (20), and (21) that $y_{H}^{*}>y_{H}^{0}$ and $y_{F}^{*}<y_{F}^{0}$. 


\section{References}

Bodnar, G. M., Hayt, G. S., \& Marston, R. C. (1998). 1998 Wharton survey of financial risk management by US non-financial firms. Financial Management, 27, 70-91.

Broll, U., Wong, K. P., \& Zilcha, I. (1999). Multiple currencies and hedging. Economica, $66,421-432$.

Broll, U., \& Zilcha, I. (1992). Exchange rate uncertainty, futures markets and the multinational firm. European Economic Review, 36, 815-826.

Committee on Payment and Settlement Systems. (1998). OTC derivatives: Settlement procedures and counterparty risk management. Bank for International Settlements, Basel, Switzerland.

Danthine, J.-P. (1978). Information, futures prices, and stabilizing speculation. Journal of Economic Theory, 17, 79-98.

Feder, G., Just, R. E., \& Schmitz, A. (1980). Futures markets and the theory of the firm under price uncertainty. Quarterly Journal of Economics, 94, 317-328.

Gollier, C. (2001). The economics of risk and time. Cambridge, MA: MIT Press.

Hogg, R. V., \& Craig, A. T. (1989). Introduction to mathematical statistics (4th ed.). New York, NY: Macmillan.

Holthausen, D. M. (1979). Hedging and the competitive firm under price uncertainty. American Economic Review, 69, 989-995.

Jorion, P. (2001). Value at risk: The new benchmark for managing financial risk (2nd ed.). New York, NY: McGraw-Hill.

Lien, D. (2003). The effect of liquidity constraints on futures hedging. Journal of Futures Markets, 23, 603-613.

Rothschild, M., \& Stiglitz, J. E. (1970). Increasing risk: I. A definition. Journal of Economic Theory, 2, 225-243.

Rothschild, M., \& Stiglitz, J. E. (1971). Increasing risk II: Its economic consequences. 
Journal of Economic Theory, 3, 66-84.

Stulz, R. M. (1996). Rethinking risk management. Journal of Applied Corporate Finance, 9, 8-24.

Tufano, P. (1996). Who manages risk? An empirical examination of risk management practices in the gold mining industry. Journal of Finance, 51, 1097-1137.

Wong, K. P. (1997). On the determinants of bank interest margins under credit and interest rate risks. Journal of Banking and Finance, 21, 251-271.

Wong, K. P. (2004a). Hedging, liquidity, and the competitive firm under price uncertainty. Journal of Futures Markets, 24, 697-706.

Wong, K. P. (2004b). Liquidity constraints and the hedging role of futures spreads. Journal of Futures Markets, 24, 909-921. 